\title{
hnRNP A1 associates with telomere ends and stimulates telomerase activity
}

\author{
QING-SHUO ZHANG, ${ }^{1}$ LISA MANCHE, RUI-MING XU, and ADRIAN R. KRAINER \\ Cold Spring Harbor Laboratory, Cold Spring Harbor, New York 11724, USA
}

\begin{abstract}
Telomerase is a ribonucleoprotein enzyme complex that reverse-transcribes an integral RNA template to add short DNA repeats to the $3^{\prime}$-ends of telomeres. G-quadruplex structure in a DNA substrate can block its extension by telomerase. We have found that hnRNP A1-which was previously implicated in telomere length regulation-binds to both single-stranded and structured human telomeric repeats, and in the latter case, it disrupts their higher-order structure. Using an in vitro telomerase assay, we observed that depletion of hnRNP A/B proteins from 293 human embryonic kidney cell extracts dramatically reduced telomerase activity, which was fully recovered upon addition of purified recombinant hnRNP A1. This finding suggests that hnRNP A1 functions as an auxiliary, if not essential, factor of telomerase holoenzyme. We further show, using chromatin immunoprecipitation, that hnRNP A1 associates with human telomeres in vivo. We propose that hnRNP A1 stimulates telomere elongation through unwinding of a G-quadruplex or G-G hairpin structure formed at each translocation step.
\end{abstract}

Keywords: G-quadruplex; hnRNP A1; processivity; telomerase; telomere

\section{INTRODUCTION}

Telomeres are specialized nucleoprotein complexes that protect the linear ends of chromosomes from degradation and fusion (Blackburn 2001). In most eukaryotes, telomeric DNA consists of TG-rich tandem repeats (5-26 bp) that range from $<30 \mathrm{nt}$ in some ciliates to $50 \mathrm{~kb}$ in mice. The repeat in mammals is TTAGGG; in Tetrahymena thermophila, it is TTGGGG; and in Oxytricha nova, it is TTTTGGGG. Most of the telomeric DNA is duplex but ends with a characteristic 3' single-stranded G-rich overhang, which is an essential feature of telomere structure and function.

Telomeres are associated with a specific set of proteins that protect the normal chromosome ends from nuclease degradation, and prevent DNA repair. In mammals, TRF2 binds to double-stranded telomeric DNA and protects the telomere ends (Smogorzewska and de Lange 2004). Another protein factor, POT1 (Baumann and Cech 2001), is thought to modulate telomere elongation (Colgin et al. 2003; Loayza and de Lange 2003). In addition to this

${ }^{1}$ Present address: Oregon Health \& Science University, Portland, OR 97239, USA.

Reprint requests to: Adrian R. Krainer, Cold Spring Harbor Laboratory, Cold Spring Harbor, NY 11724, USA; e-mail: krainer@cshl.edu; fax: (516) 367-8453.

Article published online ahead of print. Article and publication date are at http://www.rnajournal.org/cgi/doi/10.1261/rna.58806. proteinaceous cap model, telomere end protection can be achieved by a specific telomere configuration called a t-loop, in which the G-overhang loops back and invades the duplex telomere DNA.

In most human somatic cells, telomeres shorten as cells divide. However, telomeres can be elongated by telomerase (Blackburn 2001), an enzyme activated by most cancer cells to make them immortal. Telomerase is a ribonucleoprotein that adds telomeric repeats to the terminus of the G-rich overhangs, using a sequence within its associated RNA as a template. Both the protein and the RNA components of telomerase are necessary for its function. However, the minimum number of components required for activity is unknown.

Telomerase requires accessible $3^{\prime}$ overhangs for elongation. G-rich DNA can form a higher-order structure, known as a G-quadruplex (also known as G4 DNA or G-quartet), by Hoogsteen base-pairing between guanine residues. This structure makes the telomeric DNA tail inaccessible to telomerase, and thus blocks the telomerase reaction (Zahler et al. 1991). Although the extent to which telomeric DNA folds into a G-quadruplex in vivo is uncertain, small compounds that stabilize this structure in vitro, such as anthraquinone analogs and porphyrins, inhibit the telomerase reaction in cancer cells, offering an attractive approach for cancer therapy (Han and Hurley 2000). 
The hnRNP A/B family of proteins includes hnRNP A1, $\mathrm{A} 2$, and A3, each of which has multiple splicing isoforms. They have two RNA-recognition motifs (RRMs) at the N terminus, and a glycine-rich domain at the $\mathrm{C}$ terminus. hnRNP A/B proteins play various roles in mRNA metabolism, but they have also been implicated in binding to single-stranded telomeric repeats, and functions associated with telomeres. hnRNP A1 and A2 were initially characterized as single-stranded telomeric DNA-binding proteins using affinity chromatography (McKay and Cooke 1992; Ishikawa et al. 1993). Subsequently, the telomere-binding ability of hnRNP A/B proteins and UP1-an N-terminal proteolytic fragment of hnRNP Al-was confirmed (Ding et al. 1999; Dallaire et al. 2000). Although these studies clearly showed that hnRNP A1 binds specifically to telomeric DNA in vitro, it was not known whether it actually does so in vivo. Chabot and colleagues (LaBranche et al. 1998) showed that restoring hnRNP A1 or UP1 expression in a mouse hnRNP A1-deficient erythroleukemia cell line has a telomere-lengthening effect after extensive passage in culture. Because hnRNP Al but not UP1 is active in alternative splicing regulation (Mayeda et al. 1994), the telomere-lengthening effect is unlikely to be an indirect result via RNA splicing. On the other hand, it is puzzling that other closely related hnRNP A/B proteins, which might have similar telomere-lengthening functions, cannot overcome the hnRNP A1 deficiency in this cell line. Clearly, the precise contributions of hnRNP Al to telomere length regulation, and the mechanistic basis of this effect, warrant further study.

Here, our goal was to ascertain the function of hnRNP A1 (and related proteins) in telomere length regulation, and its mechanism of action. We found that hnRNP A1 has the ability to disrupt the higher-order structure of telomeric DNA, and to stimulate the telomerase reaction in vitro. Furthermore, we observed that hnRNP A1 is present at the telomere ends in vivo. Taken together, our data provide further evidence that hnRNP A1 has a bona fide role in telomere length regulation.

\section{RESULTS}

\section{UP1 binding to single-stranded human telomeric DNA in solution}

The crystal structure of a complex between UP1 and a single-stranded oligonucleotide with two human telomeric repeats (TR2) shows that a UP1 dimer binds to two antiparallel single strands of DNA, and two telomeric repeats function as a minimum binding unit (Ding et al. 1999). We first tested this model in solution using an electropho- retic mobility shift assay (EMSA) with human telomeric DNA oligonucleotides. Consistent with the crystal structure, UP1 or hnRNP A1 formed a single complex with TR2 (data not shown; Fig. 1A). Similar experiments using mutant telomeric DNA repeats and proteins showed that the binding of UP1 to TR2 is sequence-specific and requires both RRMs of UP1 and a minimum of two telomeric repeats, and that similar complexes are formed with RNA and DNA versions of the telomeric repeats (Fig. 2). We also used photochemical cross-linking and confirmed that UP1 binds to TR2 as a dimer in solution, consistent with the crystal structure (see Supplemental Fig. S1 at http://katahdin.cshl. org:9331/papers/Zhang2006RNA).

Another oligonucleotide, TR4, which comprises four repeats, or two minimum binding units, formed two distinct complexes with UP1, depending on the molar ratio of protein to DNA (Fig. 1B). Quantitative analysis showed that there was no synergistic effect observed with these two binding units (see Supplemental Fig. S2 at http://katahdin.cshl.org:9331/papers/Zhang2006RNA).

\section{UP1 binds to and disrupts structured human telomeric DNA}

UP1 can unfold G-quadruplexes formed by G-rich mammalian minisatellite DNA, inducing a characteristic conformational change detectable by CD spectroscopy (Fukuda et al. 2002). We tested whether UP1 can similarly unwind higher-order structures formed by human telomeric DNA. We prepared G-quadruplexes in a potassium-containing buffer, according to Sen and Gilbert (1990), who showed that a G-rich sequence with a $5^{\prime}$ extension, when treated to form G4 DNA, yields a product of slower electrophoretic mobility. When oligonucleotides consisting of two telomeric repeats from human, Tetrahymena, or Oxytricha were incubated at high concentrations $(400-600 \mu \mathrm{M})$ and

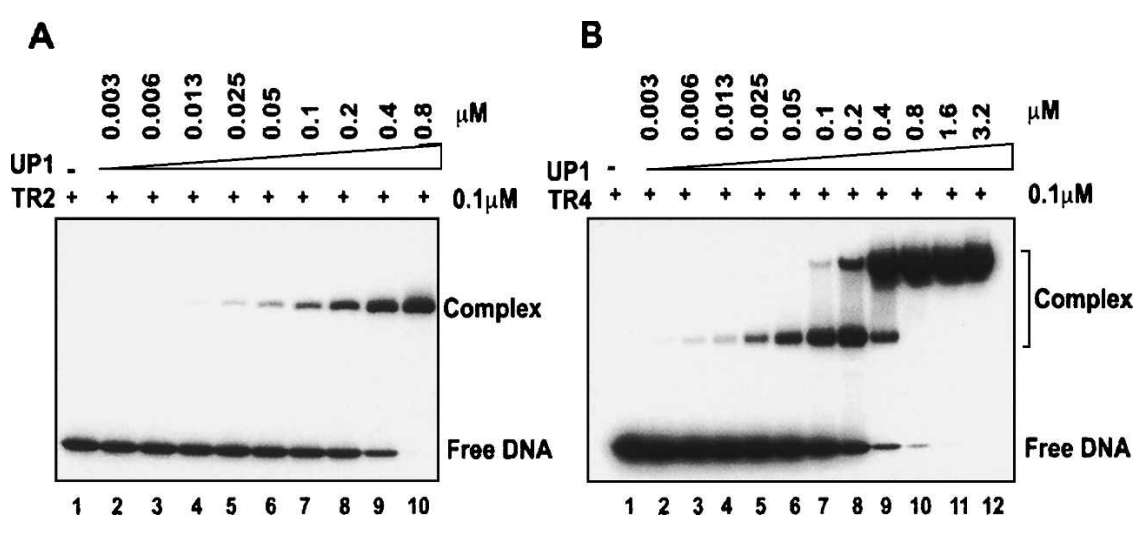

FIGURE 1. Binding of UP1 to human telomeric DNA in solution. $(A, B)$ EMSA showing the binding of recombinant human UP1 to radiolabeled oligonucleotides TR2 and TR4, respectively. The sequences are given in Table 1. Free DNA and UP1:DNA complexes were detected by autoradiography. 


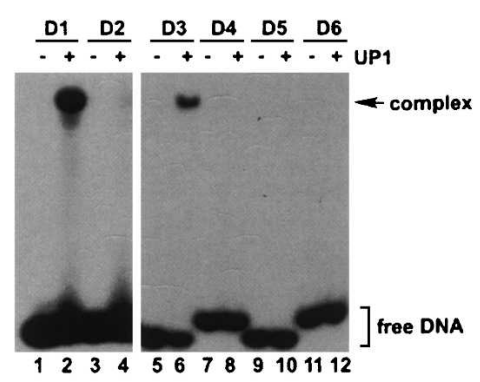

B

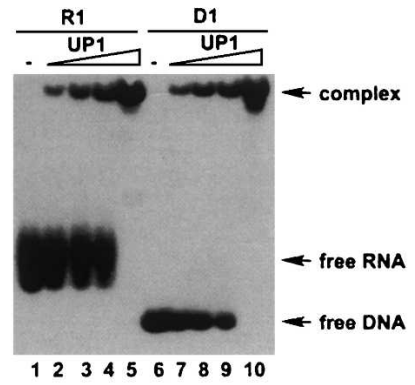

C

Ollgonucleotides:

DNA: D1: TTAGGGTTAGGG D2: TTAGGGTTAGTG D3: TAGGGTTAGG D4: TTAGGGTTTTTT D5: AAAAAATTAGG RNA: D6: TTTTTTTTAGGG

R1: UUAGGGUUAGGG

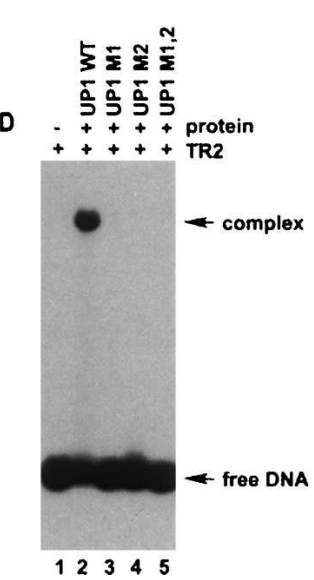

FIGURE 2. Specificity of UP1 binding to human telomeric oligonucleotides. (A) UP1 binding to wild-type and mutant telomeric oligonucleotides. The indicated oligonucleotides $(2 \mathrm{pmol})$ were incubated alone or with UP1 ( 8 pmol) and analyzed by EMSA. (B) UP1 binding to RNA and DNA oligonucleotides. Radiolabeled RNA (lanes 1-4, 2 pmol; lane 5, 400 pmol) or DNA (lanes 6-9, 2 pmol; lane 10, $400 \mathrm{pmol}$ ) oligonucleotide versions of the human telomeric repeat (two copies) were incubated with increasing amounts of UP1 (lanes 1,6, 0 pmol; lanes 2,7, 4 pmol; lanes 3,8, 6 pmol; lanes 4,9, 8 pmol; lanes $5,10,3.6 \mathrm{nmol}$ ) and analyzed by EMSA. The oligonucleotides in lanes 5 and 10 were labeled to lower specific activity for incubation at high concentrations of nucleic acid and protein. $(C)$ Oligonucleotide sequences used in panels $A$ and $B . D 1$ is the same as TR2 in Table 1. (D) Binding of different UP1 mutant proteins to TR2. The M1, M2, and M1,2 versions of UP1 have two amino acid substitutions in RRM1, RRM2, and both RRMs, respectively; the same proteins were also used in Figure 5A. The reactions included $8 \mathrm{pmol}$ of the indicated proteins and 2 pmol of TR2.

moderate $\mathrm{pH}$ (7.0-8.0), a distinct slow mobility band was observed in each case by native gel electrophoresis (Fig. 3A, lanes $1,2,4,5,7,8)$. Presumptive G-quadruplex formation by Tetrahymena or Oxytricha telomeric DNA proceeded rapidly, with $>90 \%$ yield at $55^{\circ} \mathrm{C}(\mathrm{pH} 8.0)$, and $1 \mathrm{M} \mathrm{K}^{+}$. Under the same conditions, human telomeric DNA formed presumptive G-quadruplexes slowly and in low yield, probably due to its lower $G$ content. Nevertheless, one common feature shared by all three of these higher-order structures is their high stability: Once formed, they were not disrupted by incubation at $60^{\circ} \mathrm{C}$ or by dilution with TE to a low concentration $(10 \mu \mathrm{M})$ and physiological salt condition (150 $\mathrm{mM} \mathrm{K}^{+}$).

We used a mixed-oligonucleotide strategy (Sen and Gilbert 1990) to test whether the observed higher-order

structures were indeed G-quadruplexes. The combined oligonucleotides TE1 and TE2, both of which comprise two repeats of Tetrahymena telomeric DNA but differ in the length of their $5^{\prime}$ extension, formed five distinct slowly migrating bands, as expected for tetramolecular G-quadruplexes

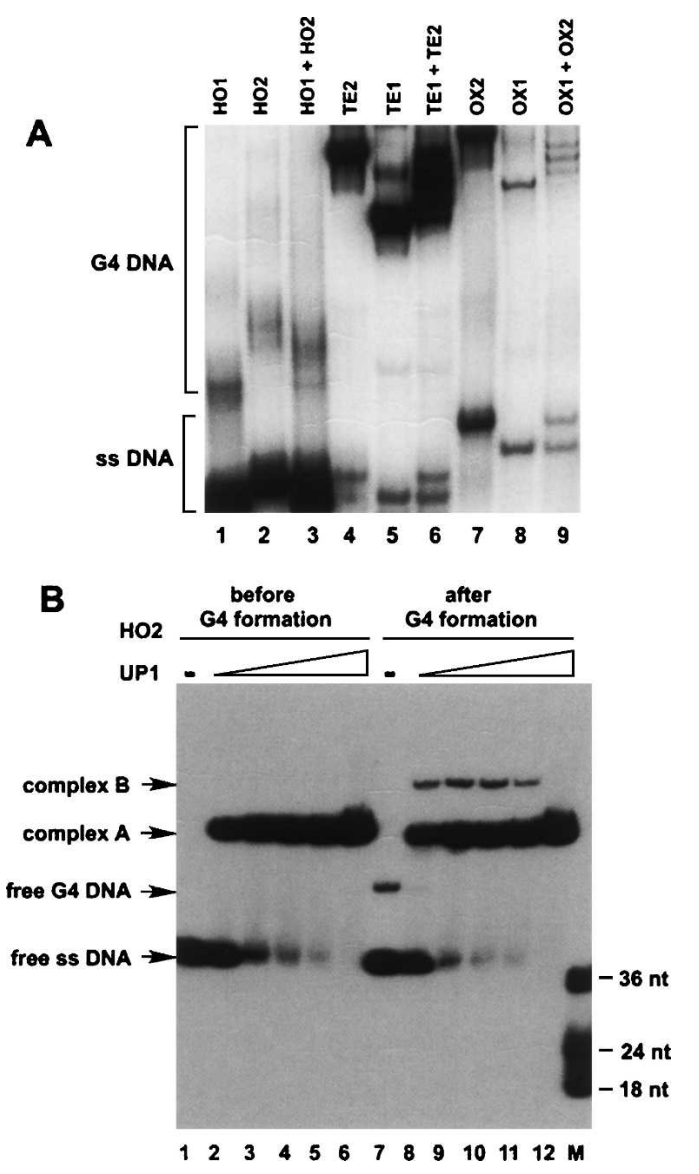

FIGURE 3. UP1 disrupts a higher-order structure formed by human telomeric DNA. (A) G-quadruplex native-gel assays (Sen and Gilbert 1990) with radiolabeled telomeric oligonucleotides from human, Tetrahymena, or Oxytricha (see Table 1 for sequences). In each case, two oligonucleotides with $5^{\prime}$ tails of different lengths were incubated separately (lanes $1,2,4,5,7,8$ ) or together (lanes $3,6,9$ ), to allow formation of higher-order structures, followed by analysis on a native gel to determine the type of G-quadruplex formed. The mobilities of the single-stranded (ss) and G4 DNAs are indicated. (B) EMSA of UP1 binding to radiolabeled human telomeric single-stranded and presumptive G-quadruplex DNAs. Increasing amounts of recombinant human UP1 (0 pmol [lanes 1,7], 20 pmol [lanes 2,8], 40 pmol [lanes 3,9], $80 \mathrm{pmol}$ [lanes 4,10], $160 \mathrm{pmol}$ [lanes 5,11], and $320 \mathrm{pmol}$ [lanes 6,12]) were incubated with single-stranded HO2 DNA (lanes 1-6) or with preformed G4 HO2 DNA plus ssDNA (lanes 7-12). The total DNA amount in each lane was 25 pmol. After incubation at room temperature for $15 \mathrm{~min}$, the reaction mixtures were analyzed by electrophoresis on a $12 \%$ native polyacrylamide gel at $4^{\circ} \mathrm{C}$, followed by autoradiography. Lane $M$ represents markers (sizes indicated at right). Complexes A and B correspond to UP1 bound to singlestranded and G4 HO2 DNAs, respectively. The mobilities of free ssDNA and G4 DNA are also indicated. Both complexes form at low UP1 concentrations, but complex B falls apart at high UP1 concentrations and converts into complex A due to unwinding of the G4 DNA. 
with four molecules stacking with each other (Sen and Gilbert 1990; Fig. 3A, lanes 4-6). Oxytricha telomeric DNA formed a type of quadruplex similar to that obtained with Tetrahymena telomeric DNA (Sen and Gilbert 1990; Fig. 3A, lanes 7-9). Notably, human telomeric DNA differed from its ciliate counterparts by forming a distinct type of higher-order structure. A mixture of oligonucleotides $\mathrm{HO} 1$ and $\mathrm{HO} 2$ formed a more compact structure with faster electrophoretic mobility than the ciliate tetramolecular G-quadruplexes (Fig. 3A, lanes 1-3). This structure is unlikely to be a G-G hairpin (Shippen-Lentz and Blackburn 1990; Jarstfer and Cech 2002) or a simple structure involving conventional base pairs, given its resistance to heat and low salt. Crystallographic studies demonstrated that human telomeric DNA can form a dimeric G-quadruplex, in which one molecule with two telomeric repeats folds back to stack with itself (Parkinson et al. 2002). The compact structure we observed with the human telomeric repeats is therefore likely to be a dimeric G-quadruplex.

Next, we tested whether recombinant UP1 could unwind the higher-order structure formed by HO2. The unstructured HO2 formed a single complex with UP1, designated A (Fig. 3B, lanes 1-6). When $\mathrm{HO} 2$ was preincubated under conditions leading to partial formation of presumptive G4 DNA, subsequent incubation with increasing amounts of UP1 gave rise to a complex designated $\mathrm{B}$, which runs more slowly than A (Fig. 3B, lanes 7-12). At a low UP1/DNA ratio, both $\mathrm{A}$ and $\mathrm{B}$ complexes were present, whereas at higher UP1/DNA ratios, B gradually dissociated, apparently changing into $\mathrm{A}$. This result, together with the previous report that UP1 can unfold mouse minisatellite G-quadruplex DNA (Fukuda et al. 2002), indicates that UP1 can bind to, and unwind, the presumptive G-quadruplex formed by human telomeric DNA repeats, suggesting a potential role of UP1 in changing the conformation of mammalian telomeres.

\section{Depletion and add-back of hnRNP A/B proteins in telomerase extracts}

Given the ability of UP1 to unwind higher-order telomeric DNA, we next tested whether hnRNP A/B proteins can affect telomerase activity in vitro. We prepared telomerase extracts from HEK293 cells, and tested whether depleting hnRNP A/B proteins interferes with the telomerase reaction (Fig. 4). To this end, we used immobilized, biotinylated single-stranded telomeric DNA repeats to selectively remove these proteins from the extracts (Zhu et al. 2001) and tested the telomerase activity. Because of the use of crude extracts, which may have telomerase inhibitors, and the scale required for depletion/add-back experiments, we could not achieve the sensitivity required to detect telomere extension by a direct telomerase assay (Morin 1989; data not shown). Instead, we relied on a widely used telomeric repeat amplification protocol (TRAP) in which a primer,
TS, is elongated by telomerase and the products are amplified by PCR, together with an internal control (Kim and Wu 1997). As confirmed by Western blotting (Fig. 4A), both hnRNP A1 and A2 were undetectable after two rounds of depletion. As a specificity control, we probed for the hnRNP C1/C2 proteins, which were only minimally depleted. Staining for total proteins in the original and depleted extracts showed no substantial changes in the major protein components of the extract (Fig. 4B). In addition, to test whether the telomerase RNP was also depleted, we used RTPCR to measure the human telomerase RNA (hTR) and found that its abundance did not change substantially before and after depletion (Fig. 4C, lanes 2,3) and no hTR bound to the beads (lane 4). Next, we monitored telomerase activity in the depleted extract using the TRAP assay, including RNase A control treatments to verify hTR-dependence (Fig. 4D). The depletion dramatically reduced telomerase activity (Fig. 4D, lanes 2-5), consistent with a role of hnRNP A/B proteins in promoting telomerase elongation. The presence of similar amounts of PCR products from the internal control excluded the possibility that the depletion had an inhibitory effect on the PCR reaction itself.

To rule out the possibility that limiting factors were codepleted with the hnRNP A/B proteins, we tested whether we could recover telomerase activity by addition of various recombinant hnRNP A/B proteins. First, based on the concentration of hnRNP A1 in the extract (Fig. 4A), we added back a comparable amount of purified recombinant hnRNP A/B proteins to the depleted extract, and measured telomerase activity by the TRAP assay (Fig. 4D, lanes 6-11). Recombinant hnRNP A1 fully restored the telomerase activity to the depleted extract. hnRNP A2, which has $68 \%$ amino acid identity with hnRNP A1, gave a similar effect, whereas UP1 had slightly weaker activity. To test the specificity of the effect of these RNA-binding proteins on telomerase activity, we also tested SF2/ASF, an abundant nuclear pre-mRNA splicing factor with two RRMs, or Gene 32 Protein (G32P), a single-strandedDNA-binding protein from bacteriophage T4. Neither protein restored telomerase activity when added to the depleted extract (Fig. 4D, lanes 12-15). Moreover, the addition of hnRNP A1 to the PCR step of the TRAP assay after the telomerase reaction had no effect, indicating that hnRNP A1 stimulates the telomerase reaction, rather than the PCR amplification step (see Supplemental Fig. S3 at http://katahdin.cshl.org:9331/papers/Zhang2006RNA). Titration of the recombinant protein further showed that hnRNP A1 promotes the telomerase reaction in a concentration-dependent manner (Fig. 4E). Taken together, the hnRNP A/B protein depletion and add-back experiments demonstrate that these proteins can potently stimulate the telomerase-dependent telomere elongation reaction.

The fact that UP1 has substantial telomerase-stimulating activity indicates that the C-terminal glycine-rich domain of hnRNP A1 is not strictly required for this function, although 

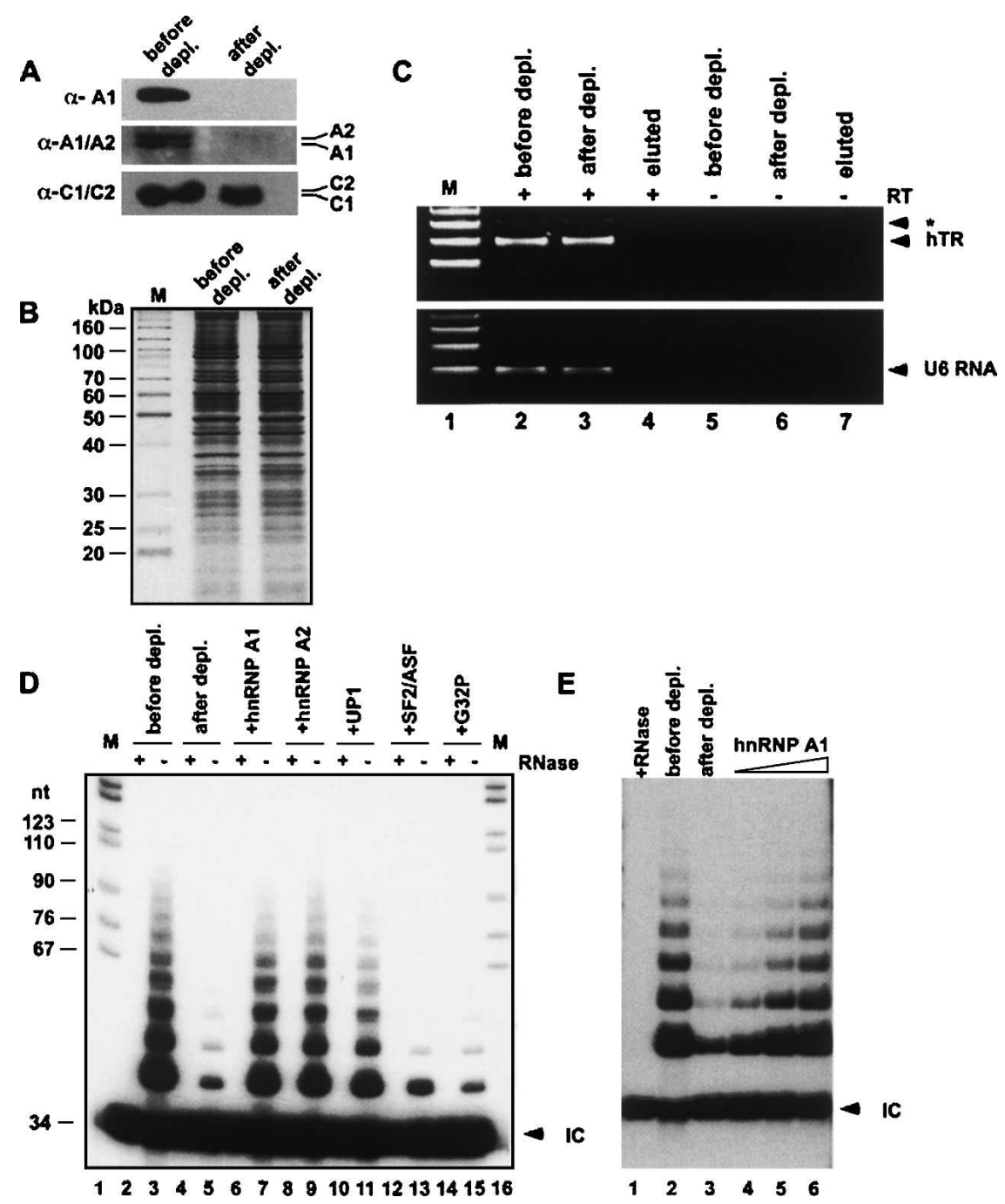

FIGURE 4. Effect of depletion and add-back of hnRNP A/B proteins on telomerase activity in HEK293 cell extracts. (A) Western blot showing the successful depletion of hnRNP A1 and A2 from telomerase extracts. mAbs 4B10 (1:1000), A1/38 (1:100), and 4F4 (1:1000) were used for detection of hnRNP A1, hnRNP A1/A2, and hnRNP C1/C2, respectively. (B) Silver staining of telomerase extracts before and after depletion of hnRNP A/B proteins. (M) Markers (sizes indicated at left). (C) RT-PCR detection of telomerase RNA before and after depletion of hnRNP A/B proteins. RNA was purified from the extracts and from the material bound to the beads, and hTR and control U6 RNAs were detected by RT-PCR (lanes 2-4). Control reactions without reverse transcriptase are also shown (lanes 5-7). The PCR products corresponding to hTR and U6 snRNA are indicated; asterisk $\left(^{*}\right)$ denotes an unknown product that was also amplified with the hTR primers. (D) Telomerase activity in the presence and the absence of hnRNP A/B proteins. The indicated recombinant proteins ( 5 pmol) were added to the depleted extract individually. For every condition, RNase A was added as a control in the indicated lanes to destroy the telomerase RNA. Telomerase activity was measured by TRAP. (M) DNA markers (sizes indicated at left), (IC) internal control PCR product. (E) Titration of recombinant hnRNP Al to show the concentration dependence of telomerase stimulatory activity. The amounts of hnRNP Al used for lanes 4-6 were $0.16,0.63$, and 2.5 pmol, respectively.

it is essential for some of this versatile protein's other functions, such as the modulation of alternative splicing (Mayeda et al. 1994). Using the affinity depletion/add-back assay, we further tested the domain requirements for the telomerase-stimulatory activity of hnRNP A1. Three RRM mutants of UP1 (Mayeda et al. 1994), in which both phenylalanines of the RNP-1 submotif in RRM1 and/or RRM2 are replaced with aspartates to disrupt nucleic acid binding, lost the ability to restore telomerase activity in the depleted extract (Fig. 5A), correlating with their failure to bind telomeric repeats (Fig. 2D). In contrast, another mutant, UP1-KYAA, in which Lys166 and Tyr167 were simultaneously replaced by alanines, maintained telomere-binding activity by EMSA (data not shown) and retained the ability to restore telomerase activity to the same level as wild-type UP1 (Fig. 5A). Thus, the telomeric DNA-binding activity mediated by both RRMs correlates with the telomerase-stimulating activity of hnRNP A1.

We then tested whether hnRNP Al's stimulatory activity can counteract the effect of a G-quadruplex-stabilizing compound. The porphyrin derivative $N$-methyl mesoporphyrin IX (NMM) binds G4 DNA, and specifically inhibits its unwinding by RecQ-family helicases (Huber et al. 2002). NMM inhibited telomerase activity in the HEK293 extract (Fig. 5B, lane 3). However, an excess of hnRNP A1 could completely overcome this inhibition by NMM (Fig. 5B, lane 4). This observation suggests that NMM is unable to block G4 unwinding by hnRNP A1, in marked contrast to the effect of this compound on the RecQ helicases.

\section{hnRNP A1 associates with telomeres in vivo}

The above data reveal a stimulatory role of hnRNP A1 in telomerase-dependent telomere elongation. However, it is not known whether hnRNP A1 can access telomere ends in vivo. hnRNP Al is an abundant protein that localizes in a diffuse nuclear pattern, and thus if a small subpopulation of hnRNP Al is associated with telomeres, it would be difficult to detect it by immunofluorescence. As telomerase was successfully detected at telomeres by chromatin immunoprecipitation (ChIP) in mammalian cells (Sharma et al. 2003), we carried out ChIP experiments in asynchronous HeLa cells to examine whether hnRNP A1 is physically associated with 
A

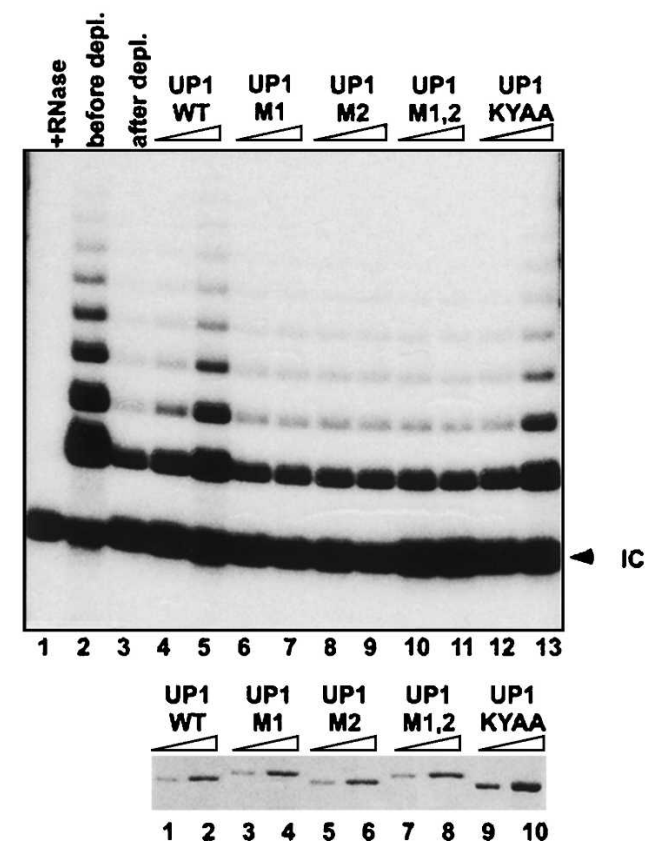

B

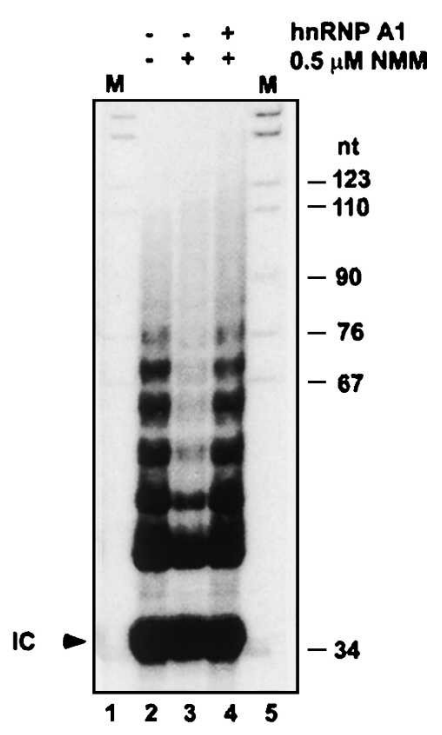

FIGURE 5. TRAP assays with UP1 mutants, and hnRNP A1 rescue of telomerase inhibition by NMM. (A) Domain requirement for the telomerase stimulatory activity of UP1. (Upper panel) Different recombinant UP1 mutant proteins (1 or $8 \mathrm{pmol}$ ) were tested for the ability to stimulate telomerase activity in hnRNP A/B-depleted extracts, as in Figure 4, D and E. M1, M2, and M1,2 versions of UP1 have mutations in RRM1, RRM2, and both RRMs, respectively, which abolish nucleic acid binding (Mayeda et al. 1994); the KYAA mutation, which does not impair binding, is described in the text. (Lower panel) Coomassie staining to show the input of different UP1 mutant proteins in the telomerase reactions. (B) NMM inhibition and rescue. The undepleted telomerase extract was used, and telomerase activity was monitored by TRAP. NMM was added at a final concentration of $0.5 \mu \mathrm{M}$ in lanes 3 and 4 . In lane 3,12.5 pmol of hnRNP Al was added to a $40-\mu \mathrm{L}$ reaction, $10 \mathrm{~min}$ after the addition of NMM. The telomerase extract was added last.

telomeres in vivo (Fig. 6). Formaldehyde-cross-linked chromatin was sheared by sonication and immunoprecipitated by antibodies against hnRNP A1, TRF2 (positive control), or SF2/ASF (negative control).

Two approaches were used to analyze the enrichment of telomeric DNA repeats in the immunoprecipitated DNA. First, slot-blot analysis was performed, and the presence of telomeric DNA was detected by hybridization with a ${ }^{32}$ P-labeled telomeric probe (Fig. 6A). We observed hnRNP A1-dependent and TRF2-dependent, but not SF2/ASFdependent, immunoprecipitation of telomeric DNA, indicating that hnRNP Al associates with telomeres in vivo. When a control probe corresponding to human total genomic DNA was used, only the input extract gave a strong positive signal. Another control probe corresponding to centromeric DNA repeats confirmed that the overall DNA amount in each slot of immunoprecipitated DNA was the same.

The slot-blot signals were then quantitated (Fig. 6B). Compared to the SF2/ASF negative control, anti-hnRNP A1 antibody resulted in a four- to sixfold enrichment of telomeric DNA, although this enrichment was not as high as that obtained with the anti-TRF2 antibody (20- to 22-fold). A stronger signal for TRF2 is expected, given that it binds all along the telomeric repeats, whereas hnRNP Al binding is likely limited to the single-stranded overhangs.

We next used a PCR approach to confirm the above observation. To avoid amplifying the simple repeat sequence of telomere tracts, we designed subtelomeric PCR primers overlapping with the last repeat of the internal end of the telomere tract in human Chromosome 4p16.3 (Fig. 6C). The sonicated chromatin was heterogeneous, ranging from 0.5 to $8 \mathrm{~kb}$, with an average size of $2 \mathrm{~kb}$. The majority of terminal restriction fragment (TRF) lengths in HeLa cells range from 3 to $7 \mathrm{~kb}$ (data not shown) including up to 5 $\mathrm{kb}$ of nontelomeric sequence. This distribution suggests that the mean length of simple telomeric repeats in HeLa cells is only a few kilobases. Therefore, it is possible to use PCR detection of telomeric signals in immunoprecipitated DNA using subtelomeric primers, even though hnRNP A1 might function along with telomerase at the extreme end of telomeres. A pair of control primers was chosen, corresponding to the same chromosome but $22 \mathrm{~kb}$ away from the end of the telomere tract. In addition, we also included as a control an antibody against the SNAP190 subunit of the snRNA-activating protein complex (SNAPc), which is required for both Pol II and Pol III transcription from snRNA promoters (Schramm et al. 2000).

DNA immunoprecipitated by the four antibodies was normalized for equal input based on the slot-blot assay with the centromeric DNA probe. After reversal of the crosslinks, DNA from non-cross-linked (Fig. 6D, lanes 1-5) and cross-linked (Fig. 6D, lanes 6-10) samples was amplified with the various primer sets to assess the cross-linkingdependent enrichment and specificity of the protein-bound DNA fragments recovered with each antibody. SNAP190 associated with the U6 core promoter, but not with a region upstream of the U6 promoter, as expected (Schramm et al. 2000), or with the subtelomeric and control regions of Chromosome 4 (Fig. 6D). Both hnRNP A1 and TRF2 associated with DNA fragments spanning the subtelomeric region of human Chromosome 4, but not with the control DNA farther toward the centromere on the same chromosome or with the U6 core promoter and U6 upstream region DNAs. In contrast, SF2/ASF did not show specific 
A

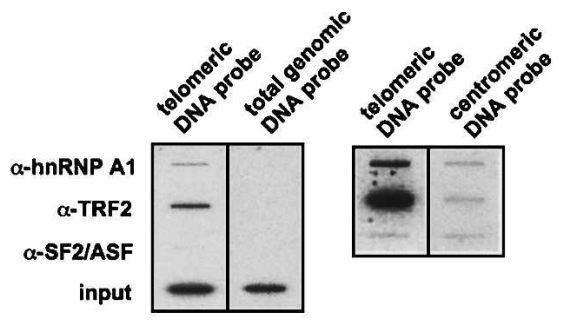

B

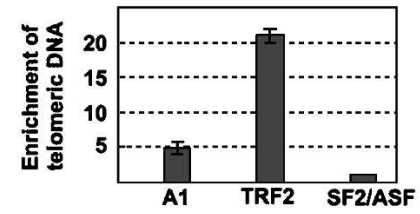

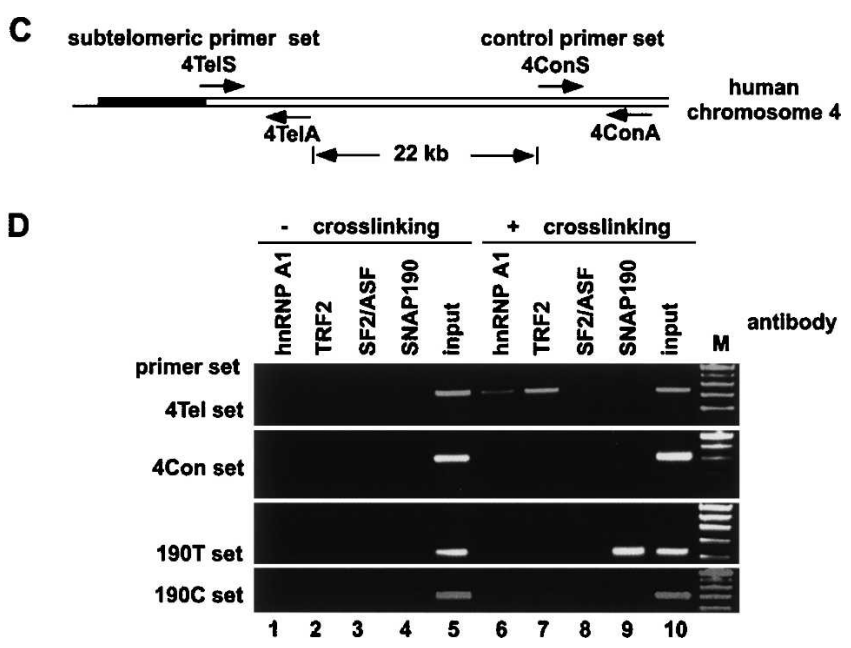

FIGURE 6. Telomeric association of hnRNP A1 determined by ChIP in asynchronous HeLa cells. (A) ChIP followed by slot-blot detection of DNA. Telomeric DNA was detected using a ${ }^{32} \mathrm{P}$-labeled telomeric probe. (Left panel) A total human genomic DNA probe was used as a negative control. (Right panel) A centromeric probe was used as a negative control, and a long exposure is shown to allow detection of the centromericrepeat background signal, which demonstrates equal DNA loading. (B) Quantitation of the slot-blot assay of ChIPed DNA by PhosphorImaging. The extent of telomeric DNA enrichment by anti-hnRNP A1 or TRF2 antibody was determined using the background signal from the antiSF2/ASF antibody as a reference, which is set at 1. (C) Location of primers used for PCR detection. The double lines represent the double-stranded human Chromosome 4, the thick black line represents the double-stranded telomere tract, and the single line represents the single-stranded 3' overhang. Sense and antisense subtelomeric (4TelS/4TelA) and control (4ConS/4ConA) primers are indicated by arrows, and their sequences are shown in Table 1. (D) PCR analysis of ChIPed DNA. The DNA input for each PCR reaction was normalized based on quantitation of the slot-blot signals with the centromeric-repeat probe. Samples derived from immunoprecipitation of non-cross-linked chromatin (lanes 1-5) and crosslinked chromatin (lanes 6-10) with the indicated antibodies are shown. After reversal of the cross-links, the DNA was amplified with the indicated primer sets: Subtelomeric (4Tel) and control (4Con) primer sets are as in C; SNAP190 test (190T) and control primer (190C) sets correspond to U6 snRNA core promoter and U6 snRNA upstream region, respectively (Schramm et al. 2000). Primer sequences are given in Table 1.

association with any of these DNA regions. We conclude that hnRNP A1 is a bona fide telomere-associated protein in vivo.

\section{DISCUSSION}

\section{hnRNP A1 stimulates telomerase activity}

Since the initial finding that hnRNP A1 binds telomeric DNA in vitro (Ishikawa et al. 1993), a major question has been whether and how hnRNP A1 regulates telomere length in vivo. Evidence for the functional involvement of hnRNP A1 in this process was obtained by genetic experiments in cell culture (LaBranche et al. 1998), although these experiments did not reveal the mechanism or totally rule out indirect effects. Here, we found that human hnRNP Al can disrupt the higher-order structure of human telomeric DNA in vitro, and showed by ChIP that some of the hnRNP A1 in human cells is telomere-associated in vivo. Furthermore, depletion of hnRNP A/B proteins from HEK293 cell extract dramatically reduced its telomerase activity, and adding back recombinant hnRNP A1 fully restored telomerase activity.

Our finding that hnRNP Al strongly stimulates the telomerase reaction sheds new light on the composition of the human telomerase complex. This ribonucleoprotein enzyme complex, when isolated from human cells, has an apparent molecular mass of $600 \mathrm{kDa}$ (Wenz et al. 2001). Although hTERT and hTR are essential core components of telomerase, other proteins have been shown to be required for telomerase activity in vitro (Holt et al. 1999; Aigner and Cech 2004; Witkin and Collins 2004). Our hnRNP A1-depletion and add-back experiments demonstrate that hnRNP A1 has a stimulatory effect on telomerase activity in vitro. The addition of recombinant hnRNP Al resulted in full recovery of telomerase activity in the depleted extract, ruling out the possibility that the stimulatory effect might be due to other proteins in the extract that were codepleted. The residual telomerase activity present in the depleted extracts may be due to trace amounts of hnRNP A/B proteins, or it could be indicative of hnRNP A/B proteins having a stimulatory role without being absolutely required for catalysis by telomerase.

Our present findings are inconsistent with a previous report that binding of hnRNP A1 or UP1 to single-stranded telomeric repeats inhibits telomerase extension in vitro, which suggested that the effect of hnRNP Al on telomere homeostasis reflects protection against nucleolytic degradation (Dallaire et al. 2000). We suggest that the reported inhibition might have been due, e.g., to the use of a GSThnRNP A1 fusion, and of UP1 prepared by thrombin digestion of a GST-UP1 fusion. Our preparations of hnRNP A1 and UP1, which were expressed in Escherichia coli 
without fusion to other proteins or tags and were highly purified, clearly stimulated telomerase activity. A stimulatory, rather than an inhibitory effect of hnRNP Al on telomerase elongation, is consistent with the recently reported function of a Caenorhabditis elegans hnRNP A/B protein ortholog, HRP-1, which promotes telomere lengthening in vivo (Joeng et al. 2004). HRP-1 shares 40\% identity with human hnRNP Al, is the only hnRNP A/B protein found in Wormbase (release WS130 at http://www. wormbase.org), and localizes mainly at the telomere ends by immunofluorescence (Joeng et al. 2004). Overexpression of HRP-1 via an extrachromosomal array led to telomere lengthening and an increase in life span; moreover, loss of the transgene in later generations abolished the telomerelengthening effect and instead resulted in gradual telomere shortening, as is usually observed in cultured human primary cells.

It remains to be determined how hnRNP A1 associates with the telomerase RNP complex. We found that hnRNP A1 cofractionated with partially purified telomerase from HEK293 cell extracts (data not shown). Previous work also showed coimmunoprecipitation of hnRNP A1 and telomerase activity from H1299 lung cancer cells (Ford et al. 2002). However, our hnRNP A/B protein-depletion experiment showed that the majority of hnRNP A/B proteins could be separated from the telomerase RNP, although this separation nearly abolished the activity of the telomerase RNP. This result contrasts with previous work on hnRNP C1/C2 proteins, which, although not essential for telomerase activity in vitro, were also found to coimmunoprecipitate with telomerase activity (Ford et al. 2002). It is possible that hnRNP A1 does not maintain a tight interaction with the telomerase RNP, but instead is recruited to the active telomerase complex either by the telomerase substrate or by other telomerase auxiliary factor(s) during telomere elongation.

We also observed that hnRNP A2 has a similar stimulatory activity as hnRNP A1 in our in vitro telomerase assay. Mouse erythroleukemia cells knocked out for hnRNP A1 have short telomeres, despite expressing normal levels of hnRNP A2 (LaBranche et al. 1998). Our finding that hnRNP A1 and A2 have similar telomerase-stimulatory activity suggests that the telomere-shortening phenotype in the knockout cells is due to the net reduction in hnRNP $\mathrm{A} / \mathrm{B}$ protein abundance.

\section{How does hnRNP A1 stimulate the telomerase reaction?}

The telomerase-associated protein factors characterized to date seem to regulate telomerase activity in different ways. Telomerase activity requires the integrity of its RNP complex. Hsp90 and p23 promote human telomerase assembly (Holt et al. 1999). Two ciliate La-motif proteins, p43 in Euplotes and p65 in Tetrahymena, stabilize the RNA subunit of telomerase (Aigner and Cech 2004; Witkin and Collins 2004). p65 also enhances telomerase RNP assembly (Prathapam et al. 2005). Our finding that the addition of hnRNP A1 to depleted extracts completely restored telomerase activity indicates that hnRNP A1, unlike the chaperone proteins Hsp90 and p23, functions downstream of telomerase RNP assembly. Furthermore, hnRNP A1 lacks a La-motif-like element, and is unlikely to be a functional human counterpart of Euplotes p43 protein.

The stimulatory activity of hnRNP Al in the telomerase reaction requires both RRM modules, as seen by the loss of activity with point mutants in either RRM. The C-terminal G-rich domain is not essential, although deleting it resulted in slightly lower activity. The specificity of the stimulatory effect is apparent from our analysis of other nucleic-acidbinding proteins. hnRNP A2, which is very closely related to hnRNP A1, was also active, whereas another protein with two RRMs, SF2/ASF, had no effect on telomerase activity. In addition, the bacteriophage single-stranded-DNAbinding protein T4 G32P had no effect in our assay and actually has been reported to inhibit telomerase at high concentrations by binding nonspecifically to the primer (Kelleher et al. 2005).

hnRNP A1 has been suggested to play a role in recruiting telomerase to telomeres by its RRM1 and RRM2 modules binding simultaneously to telomeric DNA overhangs and hTR, respectively (Fiset and Chabot 2001). However, this model is inconsistent with the crystal structure of a UP1 complex with TR2, which shows direct contacts between both RRMs and the telomeric DNA (Ding et al. 1999). In our hands, both RRM1 and RRM2 of UP1 are required for binding to TR2 by EMSA (Fig. 2), as was shown also for the RRMs of hnRNP A2 (Moran-Jones et al. 2005). We also found in the depletion experiment that hnRNP Al can be separated completely from hTR, suggesting that they do not stably interact. In addition, we observed that hnRNP A1 stimulated telomerase activity even when the nontelomeric oligonucleotide TS was used as a primer. The fact that TS lacks an hnRNP A1-binding site and fails to bind hnRNP A1 in EMSA (data not shown) argues against hnRNP A1 stimulating telomerase activity by recruiting telomerase to the substrate, at least for the first and second rounds of the extension reaction, when an hnRNP Al-binding site is not yet available.

Human POT1 rescues telomerase extension of certain poor primers that form intramolecular G-quadruplexes (Zaug et al. 2005). On the other hand, POT1 also inhibits telomerase extension of primers to which it can bind (Kelleher et al. 2005). Our telomerase assays with hnRNP A1 used the TS primer, which lacks detectable higher-order structure and is not bound by hnRNP A1 (data not shown), arguing against the possibility that hnRNP Al disrupts the higher-order structure of a telomeric primer, thereby allowing its extension by telomerase. Therefore, it seems more likely that hnRNP Al functions at the elongation 
step, rather than at the substrate-recruiting step, of the telomerase reaction.

\section{A model for hnRNP A1 stimulation of telomerase processivity}

Processive telomere extension requires a translocation step, which occurs when telomerase reaches the $5^{\prime}$ boundary of the template after the completion of one round of telomere repeat addition (Greider 1991). The formation of G-G hairpin or G-quadruplex structures has been proposed to provide the activation energy for translocation (ShippenLentz and Blackburn 1990; Zahler et al. 1991). However, a stable G-G hairpin or G-quadruplex structure might be an obstacle to the telomerase reaction in subsequent rounds of extension. Accordingly, it was suggested that the formation of a G-G hairpin might be sufficiently transient during the telomerase reaction cycle, whereas a G-quadruplex might be too difficult to disrupt, and therefore might not form at all during the reaction cycle (Jarstfer and Cech 2002).

In this work, we observed that UP1 can bind to, and disrupt, presumptive dimeric G-quadruplexes formed by human telomeric repeats. This result is consistent with a previous study showing that UP1 can unfold a G-quadruplex formed by the G-rich strand of minisatellite repeats, d(GGCAG)n (Fukuda et al. 2002). Shamoo and colleagues (Myers et al. 2003) also reported that UP1 can reduce the $T_{\mathrm{m}}$ of the human telomeric oligonucleotide $\mathrm{d}$ (TAGGGT) ${ }_{4}$ in a $150 \mathrm{mM} \mathrm{K} \mathrm{K}^{+}$-containing solution, from $67.0^{\circ} \mathrm{C}$ to $36.1^{\circ} \mathrm{C}$, consistent with a G-quadruplex-destabilizing activity of UP1. Although not proven, it seems likely that hnRNP A1 can also disrupt a G-G hairpin, as hnRNP A/B proteins are well known to have nucleic acid helix-destabilizing activity (Riva et al. 1986). Therefore, it is possible that hnRNP A1 increases telomerase processivity through the disruption of the higher-order structure that drives the translocation after one round of extension but blocks the next round of extension. Consistent with this idea, we found that hnRNP A1 can overcome the inhibition of telomerase activity by NMM, a G4-unwinding inhibitor.

Another hnRNP protein, hnRNP D, which resembles hnRNP A/B proteins, has also been shown to bind to the human telomeric G-rich strand and destabilize intramolecular G-G pairing or G-quadruplexes (Eversole and Maizels 2000; Enokizono et al. 2005). Moreover, hnRNP $\mathrm{D}$ can pull down telomerase activity from extracts of a human fibrosarcoma line (Eversole and Maizels 2000), and an RRM2 fragment of hnRNP D inhibits telomerase activity in vitro (Enokizono et al. 2005). It remains to be determined whether full-length hnRNP D, like hnRNP A1, can stimulate telomerase activity. Similarly, other human proteins capable of unwinding G4 and related structures, such as BLM and WRN, could affect telomerase activity (Huber et al. 2002), although this remains to be determined.
Based on the evidence discussed above, we propose a hypothetical model for the role of hnRNP A1 in the regulation of telomerase activity (Fig. 7). This model proposes that hnRNP A1 facilitates the translocation step. First, when telomerase reaches the $5^{\prime}$ boundary of its template, a G-G hairpin or G-quadruplex structure upstream of the primer is formed and unwinds the DNA-RNA hybrid. Then, the active site/template RNA of telomerase is repositioned so that the extended primer anneals to the $3^{\prime}$ part of the template. Finally, during the course of nucleotide addition, hnRNP A1, which might be part of the telomerase holoenzyme or might be recruited by other factor(s) or the primer itself, binds to and disrupts the G-G hairpin or G-quadruplex and releases the last telomeric repeat, enabling formation of the next higher-order structure that is needed for subsequent translocation.

Precisely what kind of higher-order structure is actually formed remains to be determined. The observation that a G-quadruplex is visualized in vivo at telomere ends by use of G-quadruplex-directed antibodies or a fluorescent carbazole derivative is consistent with, though it does not prove, the existence of G-quadruplexes in vivo (Schaffitzel et al. 2001; Chang et al. 2004). An intermolecular G-quadruplex can be formed by two G-G hairpins in two primer molecules. Both X-ray and NMR structures of human telomeric repeat G-quadruplexes showed that human telomeric DNA can form either parallel or antiparallel dimeric G-quadruplexes in the presence of $\mathrm{K}^{+}$or $\mathrm{Na}^{+}$ (Wang and Patel 1993; Parkinson et al. 2002). We also observed that two repeats of human telomeric DNA appear to form a dimeric higher-order structure, as measured by EMSA. Furthermore, because telomerase was proposed to function as a multimer in some species (Prescott and Blackburn 1997), the functional dimerization of telomerase would make possible the formation of an intermolecular G-quadruplex between two primers when two chromosome ends are simultaneously extended. Compelling evidence supports the functional dimerization of human telomerase (Beattie et al. 2001; Wenz et al. 2001). It has also been suggested that multimerization might confer repeat addition processivity as an advantage to the catalytic reaction (Moriarty et al. 2004). The formation of G-quadruplex structures could be facilitated by certain telomere-associated proteins, such as yeast Rap1 and the $\beta$-subunit of Oxytricha OnTEBP, which have been shown to promote G-quadruplex assembly in vitro (Fang and Cech 1993; Giraldo and Rhodes 1994; Paeschke et al. 2005).

Our model leaves open the question of whether hnRNP A1 remains bound to the substrate after the dissociation of the higher-order structure. Although hnRNP A1 has high affinity for single-stranded telomeric repeats, it may be displaced by other telomere-binding proteins, such as POT1 (Baumann and Cech 2001), which can bind to, and protect, the newly synthesized DNA in vivo.

Telomerase processivity plays a crucial role in telomere maintenance in vivo. By apparently changing telomerase 


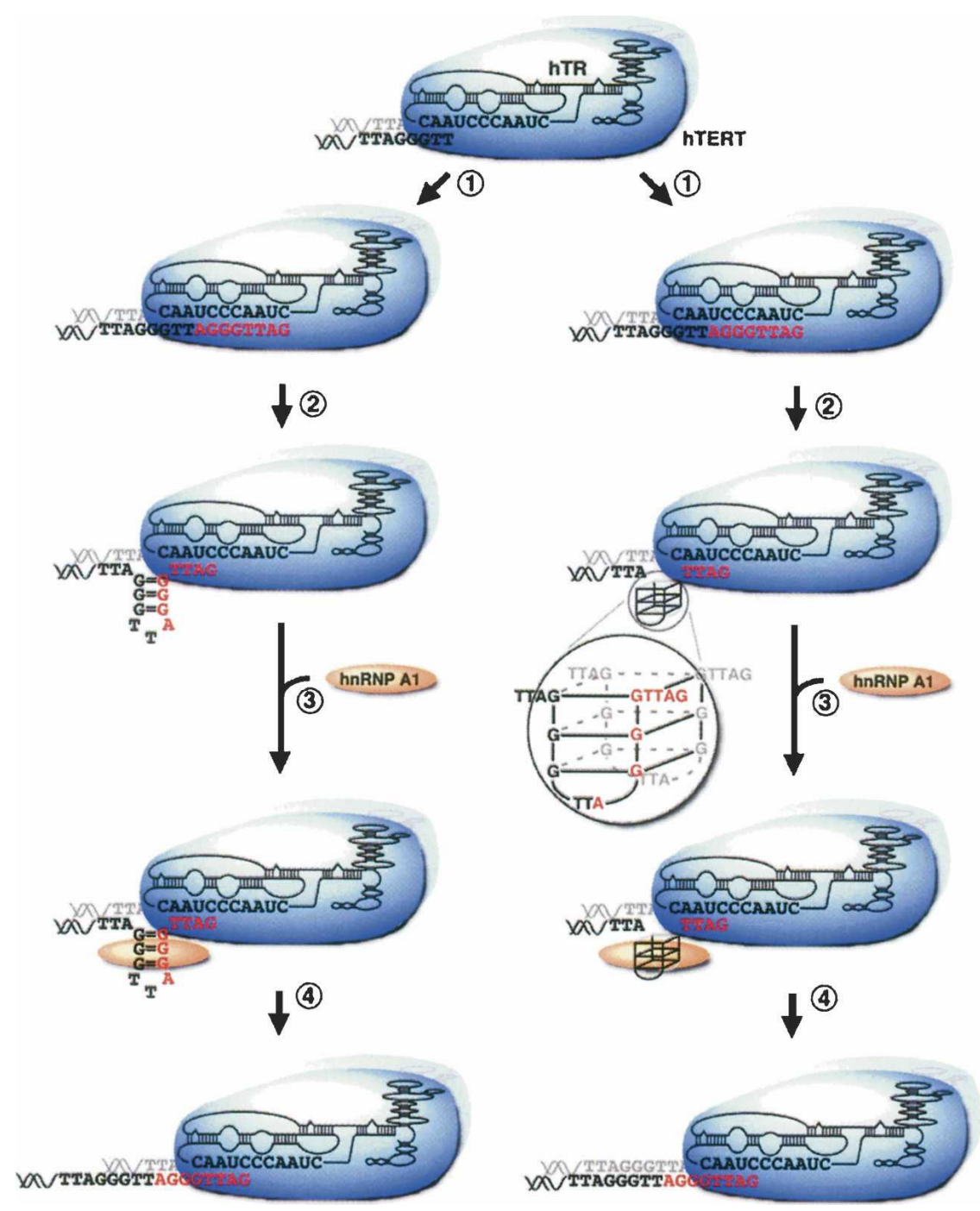

FIGURE 7. A hypothetical model showing how hnRNP Al may facilitate telomerase translocation. The secondary structure of human telomerase RNA (hTR) is based on a published model (Chen and Greider 2004). Step 1, extension of the telomere end by telomerase until the $5^{\prime}$ boundary of the template is reached; step 2, depending on whether the two aligned chromosome ends are extended simultaneously or not, either a G-quadruplex (right pathway) or a G-G hairpin (left pathway) is formed to disrupt the RNA-DNA hybrid and drive the realignment of the extended chromosome end(s) with the telomerase RNA(s); step 3, binding of hnRNP A1 to the higher-order structure, leading to step 4, unwinding of the higher-order structure in preparation for addition of the next repeat.

processivity, hnRNP A1 is able to generate a significant increase in telomere length. This mechanism is consistent with the telomere lengthening observed in C. elegans upon overexpression of HRP-1 (Joeng et al. 2004), as well as in an hnRNP A1-deficient mouse cell line after reintroduction of hnRNP A1 or UP1 (LaBranche et al. 1998). Moreover, RNAi-mediated silencing of hnRNP A1/A2 in a variety of cancer cell lines was reported to induce cell death associated with a change in the distribution of G-tail length (Patry et al. 2003). Therefore, understanding how telomerase activity is regulated by hnRNP A1 will help to understand the mechanisms of tumorigenesis, as well as the develop- ment of cancer therapies, e.g., via Gquadruplex-stabilizing compounds. Future studies will be required to obtain direct evidence of the presence of G-quadruplex or similar higher-order structures during the telomerase reaction.

\section{MATERIALS AND METHODS}

\section{Oligonucleotides and proteins}

Oligonucleotides, listed in Table 1, were obtained from Sigma Genosys and labeled with ${ }^{32} \mathrm{P}$ using T4 DNA polynucleotide kinase. hnRNP A1, hnRNP A2, UP1, and UP1 mutant proteins were expressed in $E$. coli and purified as described (Mayeda et al. 1994). Recombinant SF2/ASF, purified from E. coli, was a gift from Z. Zhang. T4 G32P was purchased from New England Biolabs.

\section{EMSA}

The binding reactions were carried out in $20 \mathrm{mM}$ HEPES/KOH ( $\mathrm{pH} \mathrm{8.0),} 50 \mathrm{mM} \mathrm{KCl}$, $1 \mathrm{mM}$ EDTA, $5 \mathrm{mM} \mathrm{MgCl}, 0.1 \mathrm{mg} / \mathrm{mL}$ yeast tRNA, $0.1 \mathrm{mg} / \mathrm{mL}$ BSA, $5 \mathrm{mM}$ dithiothreitol, and $10 \%(\mathrm{v} / \mathrm{v})$ glycerol for $10 \mathrm{~min}$ on ice. The products were separated on a $5 \%$ native polyacrylamide gel in $40 \mathrm{mM}$ Tris-glycine buffer at $4^{\circ} \mathrm{C}$, unless otherwise specified.

$\mathrm{G} 4$ formation experiments were done as described (Sen and Gilbert 1990). The products were diluted with TE to a final concentration of $25 \mu \mathrm{M}$. Twenty-five pmol of DNA was loaded onto a $15 \%$ native polyacrylamide gel. Electrophoresis was carried out in $0.5 \times$ TBE buffer supplemented with $5 \mathrm{mM}$ $\mathrm{KCl}$ at $150 \mathrm{~V}$ and $4^{\circ} \mathrm{C}$.

\section{Telomerase extract preparation and TRAP assay}

Telomerase extract was prepared from HEK293 cells in CHAPS lysis buffer (Kim and $\mathrm{Wu}$ 1997). The TRAP assay was performed as a two-step reaction. First, standard TS primer was elongated by telomerase. The $40-\mu \mathrm{L}$ reaction mixture contained $50 \mathrm{mM}$ Tris-OAc (pH 8.5), $50 \mathrm{mM} \mathrm{KOAc,} 3 \mathrm{mM} \mathrm{MgCl}_{2}, 5 \mathrm{mM}$ $\beta$-mercaptoethanol, $1 \mathrm{mM}$ spermidine, $0.1 \mathrm{mg} / \mathrm{mL}$ BSA, $2 \mathrm{mM}$ $\mathrm{d}(\mathrm{ATP}, \mathrm{TTP}, \mathrm{GTP}), 0.88 \mu \mathrm{M}$ TS, and $0.3 \mu \mathrm{L}$ of telomerase extract (1.5 $\mu \mathrm{g}$ of total protein). Then, $10 \mu \mathrm{L}$ of first-step product was used for PCR amplification along with an internal PCR control template, TSNT. Each $40-\mu \mathrm{L}$ PCR reaction contained $1 \times$ AmpliTaq buffer, $0.25 \mu \mathrm{M}$ NT, $0.25 \mu \mathrm{M}$ ACT, $0.25 \mu \mathrm{M}^{32} \mathrm{P}$-labeled TS, $0.25 \mathrm{fM}$ TSNT, and $2.5 \mathrm{U}$ of AmpliTaq polymerase (Roche). The internal control PCR with primers NT and ACT generates a 36-bp product. The telomerase products with primers TS and ACT are a characteristic 6-bp ladder starting from $44 \mathrm{bp}$. PCR products 
TABLE 1. Oligonucleotides used in this work

\begin{tabular}{|c|c|}
\hline TR2 & 5'-TTAGGGTTAGGG-3' \\
\hline TR3 & 5'-biotin-TTAGGGTTAGGGTTAGGG-3' \\
\hline TR4 & 5'-TTAGGGTTAGGGTTAGGGTTAGGG-3' \\
\hline HO1 & 5'-ACTGTCGTACTTGATATTAGGGTTAGGG-3' \\
\hline $\mathrm{HO} 2$ & 5'-ACTGTCGTACTTGATACTGTCGCACTATTAGGGTTAGGG-3' \\
\hline TE1 & 5'-ACTGTCGTACTTGATATTGGGGTTGGGG-3' \\
\hline TE2 & 5'-ACTGTCGTACTTGATACTGTCGCACTATTGGGGTTGGGG-3' \\
\hline OX1 & 5'-ACTGTCGTACTTGATATTTTTGGGGTTTTGGGG-3' \\
\hline OX2 & 5'-ACTGTCGTACTTGATACTGTCGСАСТАTTTTGGGGTTTTGGGG-3' \\
\hline TS & 5'-AATCCGTCGAGCAGAGTT-3' \\
\hline ACT & 5'-GCGCGGCTAACCCTAACCCTAACC-3' \\
\hline TSNT & 5'-AATCCGTCGAGCAGAGTTAAAAGGCCGAGAAGCGAT-3' \\
\hline NT & 5'-ATCGCTTCTCGGCCTTTT-3' \\
\hline TercS & 5'-CCTGCCGCСTTCCACCGTTC-3' \\
\hline TercA & 5'-CTGACAGAGCCСАAСТCTTCGC-3' \\
\hline U6S & 5'-CTCGCTTCGGCAGCACATATAC-3' \\
\hline U6A & 5'-GGAACGCTTCACGAATTTGCGTG-3' \\
\hline 4TelS & 5'-TAACССТСАTTATTCTCGGCTGC-3' \\
\hline $4 \mathrm{TelA}$ & 5'-GAGCATCGCGAAGGAGGAGCT-3' \\
\hline 4Cons & 5'-CTGGATGGAGGCTGCTGCTGG-3' \\
\hline 4ConA & 5'-GGAGACCTTCTTCTGGACCAGC-3' \\
\hline CenW5 & 5'-AATCTGCAAGTGGATATTTGGACG-3' \\
\hline CenW3 & 5'-AGGAAGGTTCAACTCTGTGAGTTG-3' \\
\hline 190T-S & 5'-TTCTTGGGTAGTTTGCAG-3' \\
\hline 190T-A & 5'-GTTTCGTCCTTTCCACAAG-3' \\
\hline 190C-S & 5'-TAGCTCTCAAAGCCTGAG-3' \\
\hline 190C-A & 5'-GGCTGGGTTCAACTCTAC-3' \\
\hline
\end{tabular}

Telomeric repeats are shown in bold.

were analyzed by electrophoresis on a $10 \%$ polyacrylamide/7 M urea gel.

For telomerase assays in the presence of NMM (Frontier Scientific, Inc), the first-step product of the TRAP assay was purified by phenol-chloroform extraction and ethanol precipitation before the PCR amplification step.

\section{Depletion of hnRNP A/B proteins from HEK293 telomerase extract}

hnRNP A/B proteins were affinity-depleted by incubation of telomerase extracts with 5' -biotinylated TR3 oligonucleotide (Table 1) immobilized on streptavidin-agarose as described (Zhu et al. 2001), but using CHAPS lysis buffer with $150 \mathrm{mM} \mathrm{KCl}$. The depletion efficiency and specificity were monitored by Western blotting using mAbs 4B10 and 4F4 (gifts from G. Dreyfuss) against hnRNP A1 and hnRNP C1/C2, and mAb A1/38 (made in our lab) against both hnRNP A1 and A2. Silver staining after SDS-PAGE used a Silver Stain Plus Kit (Bio-Rad). RT-PCR was performed to measure the abundance of telomerase RNA in the extracts. RNA was recovered from extracts by phenol-chloroform extraction and ethanol precipitation. RNA bound to the beads was eluted with $0.2 \%$ SDScontaining lysis buffer, and purified by phenol-chloroform extraction. RNA samples were digested with RNase-free DNase I, followed by phenol-chloroform extraction and ethanol precipitation. For the U6 control, reverse transcription was primed with random hexamers; for the telomerase RNA, a gene-specific primer, TercA, was used. The PCR primers were TercS and TercA for hTR and U6S and U6A for U6 RNA (Table 1). The expected PCR products for U6 and hTR are $96 \mathrm{bp}$ and $184 \mathrm{bp}$, respectively.

\section{Chromatin immunoprecipitation}

The ChIP assays were carried out as described (Schramm et al. 2000) using asynchronous HeLa cells. Chromatin was sonicated to generate DNA fragments with an average size of $2 \mathrm{~kb}$. Immunoprecipitation was carried out overnight at $4^{\circ} \mathrm{C}$ using antibodies against hnRNP A1 (mAb 4B10), TRF2 (polyAb sc-9143; Santa Cruz Biotechnology), SF2/ASF (mAb AK96; made in our lab), or the SNAP190 subunit of SNAPc (polyAb CS696; gift from N. Hernandez). For PCR amplification of subtelomeric DNA and its corresponding control, primers were designed based on the sequence of human Chromosome 4. Primer set 4TelS/4TelA generated a 222-bp subtelomeric signal, whereas 4ConS/4ConA amplified a 301-bp sequence $22 \mathrm{~kb}$ away from the telomere region. PCR was done at $65^{\circ} \mathrm{C}$ for 25 cycles. PCR analysis of the ChIPed DNA by anti-SNAP190 subunit was done as described using test primers (190T-S/190T-A) specific for the U6 core promoter or control primers (190C-S/190C-A) corresponding to a region upstream of a U6 snRNA gene (Schramm et al. 2000). For Southern blotting of ChIPed DNA, the telomeric DNA probe was generated by random priming using a $600-b p\left(T_{2} A_{3}\right) n$ double-stranded DNA fragment as a template (gift from A. Kass-Eisler), whereas control probes were made either by random priming with human total genomic DNA as a template, or by hot PCR using primers CenW5 and CenW3 designed according to a 136-bp consensus sequence of human centromere repeats. 


\section{ACKNOWLEDGMENTS}

We thank Cathleen Collins, Richard Ebright, Gregg Morin, Peggy Farnham, and Emery Bresnick for valuable advice. We are grateful to Nouria Hernandez and Gideon Dreyfuss for antibodies, Alyson Kass-Eisler and Michelle Hastings for helpful discussions, and Zuo Zhang for recombinant SF2/ASF and critical reading of the manuscript. This work was supported by grant CA13106 from the NCI.

Received January 27, 2006; accepted February 10, 2006.

\section{REFERENCES}

Aigner, S. and Cech, T.R. 2004. The Euplotes telomerase subunit p43 stimulates enzymatic activity and processivity in vitro. RNA 10: 1108-1118.

Baumann, P. and Cech, T.R. 2001. Pot1, the putative telomere endbinding protein in fission yeast and humans. Science 292: 1171-1175.

Beattie, T.L., Zhou, W., Robinson, M.O., and Harrington, L. 2001. Functional multimerization of the human telomerase reverse transcriptase. Mol. Cell. Biol. 21: 6151-6160.

Blackburn, E.H. 2001. Switching and signaling at the telomere. Cell 106: 661-673.

Chang, C.C., Kuo, I.C., Ling, I.F., Chen, C.T., Chen, H.C., Lou, P.J., Lin, J.J., and Chang, T.C. 2004. Detection of quadruplex DNA structures in human telomeres by a fluorescent carbazole derivative. Anal. Chem. 76: 4490-4494.

Chen, J.L. and Greider, C.W. 2004. Telomerase RNA structure and function: Implications for dyskeratosis congenita. Trends Biochem. Sci. 29: 183-192.

Colgin, L.M., Baran, K., Baumann, P., Cech, T.R., and Reddel, R. 2003. Human POT1 facilitates telomere elongation by telomerase. Curr. Biol. 13: 942-946.

Dallaire, F., Dupuis, S., Fiset, S., and Chabot, B. 2000. Heterogeneous nuclear ribonucleoprotein A1 and UP1 protect mammalian telomeric repeats and modulate telomere replication in vitro. J. Biol. Chem. 275: 14509-14516.

Ding, J., Hayashi, M.K., Zhang, Y., Manche, L., Krainer, A.R., and $\mathrm{Xu}$, R.M. 1999. Crystal structure of the two-RRM domain of hnRNP A1 (UP1) complexed with single-stranded telomeric DNA. Genes \& Dev. 13: 1102-1115.

Enokizono, Y., Konishi, Y., Nagata, K., Ouhashi, K., Uesugi, S., Ishikawa, F., and Katahira, M. 2005. Structure of hnRNP D complexed with single-stranded telomere DNA and unfolding of the quadruplex by heterogeneous nuclear ribonucleoprotein $\mathrm{D}$. J. Biol. Chem. 280: 18862-18870.

Eversole, A. and Maizels, N. 2000. In vitro properties of the conserved mammalian protein hnRNP D suggest a role in telomere maintenance. Mol. Cell. Biol. 20: 5425-5432.

Fang, G. and Cech, T.R. 1993. Characterization of a G-quartet formation reaction promoted by the $\beta$-subunit of the Oxytricha telomere-binding protein. Biochemistry 32: 11646-11657.

Fiset, S. and Chabot, B. 2001. hnRNP A1 may interact simultaneously with telomeric DNA and the human telomerase RNA in vitro. Nucleic Acids Res. 29: 2268-2275.

Ford, L.P., Wright, W.E., and Shay, J.W. 2002. A model for heterogeneous nuclear ribonucleoproteins in telomere and telomerase regulation. Oncogene 21: 580-583.

Fukuda, H., Katahira, M., Tsuchiya, N., Enokizono, Y., Sugimura, T., Nagao, M., and Nakagama, H. 2002. Unfolding of quadruplex structure in the G-rich strand of the minisatellite repeat by the binding protein UP1. Proc. Natl. Acad. Sci. 99: 12685-12690.

Giraldo, R. and Rhodes, D. 1994. The yeast telomere-binding protein RAP1 binds to and promotes the formation of DNA quadruplexes in telomeric DNA. EMBO J. 13: 2411-2420.
Greider, C.W. 1991. Telomerase is processive. Mol. Cell. Biol. 11: $4572-4580$.

Han, H. and Hurley, L.H. 2000. G-quadruplex DNA: A potential target for anti-cancer drug design. Trends Pharmacol. Sci. 21: 136142.

Holt, S.E., Aisner, D.L., Baur, J., Tesmer, V.M., Dy, M., Ouellette, M., Trager, J.B., Morin, G.B., Toft, D.O., Shay, J.W., et al. 1999. Functional requirement of p23 and Hsp90 in telomerase complexes. Genes \& Dev. 13: 817-826.

Huber, M.D., Lee, D.C., and Maizels, N. 2002. G4 DNA unwinding by BLM and Sgs1p: Substrate specificity and substrate-specific inhibition. Nucleic Acids Res. 30: 3954-3961.

Ishikawa, F., Matunis, M.J., Dreyfuss, G., and Cech, T.R. 1993. Nuclear proteins that bind the pre-mRNA $3^{\prime}$ splice site sequence $r(U U A G / G)$ and the human telomeric DNA sequence d(TTAGGG)n. Mol. Cell. Biol. 13: 4301-4310.

Jarstfer, M.B. and Cech, T.R. 2002. Effects of nucleotide analogues on Euplotes aediculatus telomerase processivity: Evidence for productassisted translocation. Biochemistry 41: 151-161.

Joeng, K.S., Song, E.J., Lee, K.J., and Lee, J. 2004. Long lifespan in worms with long telomeric DNA. Nat. Genet. 36: 607-611.

Kelleher, C., Kurth, I., and Lingner, J. 2005. Human protection of telomeres 1 (POT1) is a negative regulator of telomerase activity in vitro. Mol. Cell. Biol. 25: 808-818.

Kim, N.W. and Wu, F. 1997. Advances in quantification and characterization of telomerase activity by the telomeric repeat amplification protocol (TRAP). Nucleic Acids Res. 25: 2595-2597.

LaBranche, H., Dupuis, S., Ben-David, Y., Bani, M.R., Wellinger, R.J., and Chabot, B. 1998. Telomere elongation by hnRNP Al and a derivative that interacts with telomeric repeats and telomerase. Nat. Genet. 19: 199-202.

Loayza, D. and de Lange, T. 2003. POT1 as a terminal transducer of TRF1 telomere length control. Nature 423: 1013-1018.

Mayeda, A., Munroe, S.H., Cáceres, J.F., and Krainer, A.R. 1994. Function of conserved domains of hnRNP A1 and other hnRNP A/B proteins. EMBO J. 13: 5483-5495.

McKay, S.J. and Cooke, H. 1992. hnRNP A2/B1 binds specifically to single stranded vertebrate telomeric repeat TTAGGGn. Nucleic Acids Res. 20: 6461-6464.

Moran-Jones, K., Wayman, L., Kennedy, D.D., Reddel, R.R., Sara, S., Snee, M.J., and Smith, R. 2005. hnRNP A2, a potential ssDNA/ RNA molecular adapter at the telomere. Nucleic Acids Res. 33: 486-496.

Moriarty, T.J., Marie-Egyptienne, D.T., and Autexier, C. 2004. Functional organization of repeat addition processivity and DNA synthesis determinants in the human telomerase multimer. Mol. Cell. Biol. 24: 3720-3733.

Morin, G.B. 1989. The human telomere terminal transferase enzyme is a ribonucleoprotein that synthesizes TTAGGG repeats. Cell 59: 521-529.

Myers, J.C., Moore, S.A., and Shamoo, Y. 2003. Structure-based incorporation of 6-methyl-8-(2-deoxy- $\beta$-ribofuranosyl)isoxanthopteridine into the human telomeric repeat DNA as a probe for UP1 binding and destabilization of G-tetrad structures. J. Biol. Chem. 278: 4230042306.

Paeschke, K., Simonsson, T., Postberg, J., Rhodes, D., and Lipps, H.J. 2005. Telomere end-binding proteins control the formation of G-quadruplex DNA structures in vivo. Nat. Struct. Mol. Biol. 12: 847-854.

Parkinson, G.N., Lee, M.P., and Neidle, S. 2002. Crystal structure of parallel quadruplexes from human telomeric DNA. Nature 417: 876-880.

Patry, C., Bouchard, L., Labrecque, P., Gendron, D., Lemieux, B., Toutant, J., Lapointe, E., Wellinger, R., and Chabot, B. 2003. Small interfering RNA-mediated reduction in heterogeneous nuclear ribonucleoparticule A1/A2 proteins induces apoptosis in human cancer cells but not in normal mortal cell lines. Cancer Res. 63: 7679-7688. 
Prathapam, R., Witkin, K.L., O'Connor, C.M., and Collins, K. 2005. A telomerase holoenzyme protein enhances telomerase RNA assembly with telomerase reverse transcriptase. Nat. Struct. Mol. Biol. 12: 252-257.

Prescott, J. and Blackburn, E.H. 1997. Functionally interacting telomerase RNAs in the yeast telomerase complex. Genes \& Dev. 11: $2790-2800$

Riva, S., Morandi, C., Tsoulfas, P., Pandolfo, M., Biamonti, G., Merrill, B., Williams, K.R., Multhaup, G., Beyreuther, K., Werr, H., et al. 1986. Mammalian single-stranded DNA binding protein UP I is derived from the hnRNP core protein A1. EMBO J. 5: 22672273.

Schaffitzel, C., Berger, I., Postberg, J., Hanes, J., Lipps, H.J., and Pluckthun, A. 2001. In vitro generated antibodies specific for telomeric guanine-quadruplex DNA react with Stylonychia lemnae macronuclei. Proc. Natl. Acad. Sci. 98: 8572-8577.

Schramm, L., Pendergrast, P.S., Sun, Y., and Hernandez, N. 2000. Different human TFIIIB activities direct RNA polymerase III transcription from TATA-containing and TATA-less promoters. Genes \& Dev. 14: 2650-2663.

Sen, D. and Gilbert, W. 1990. A sodium-potassium switch in the formation of four-stranded G4-DNA. Nature 344: 410-414.

Sharma, G.G., Gupta, A., Wang, H., Scherthan, H., Dhar, S., Gandhi, V., Iliakis, G., Shay, J.W., Young, C.S., and Pandita, T.K. 2003. hTERT associates with human telomeres and enhances genomic stability and DNA repair. Oncogene 22: 131-146.

Shippen-Lentz, D. and Blackburn, E.H. 1990. Functional evidence for an RNA template in telomerase. Science 247: 546-555.

Smogorzewska, A. and de Lange, T. 2004. Regulation of telomerase by telomeric proteins. Annu. Rev. Biochem. 73: 177-208.

Wang, Y. and Patel, D.J. 1993. Solution structure of the human telomeric repeat d[AG3(T2AG3)3] G-tetraplex. Structure 1: 263-282.

Wenz, C., Enenkel, B., Amacker, M., Kelleher, C., Damm, K., and Lingner, J. 2001. Human telomerase contains two cooperating telomerase RNA molecules. EMBO J. 20: 3526-3534.

Witkin, K.L. and Collins, K. 2004. Holoenzyme proteins required for the physiological assembly and activity of telomerase. Genes \& Dev. 18: $1107-1118$.

Zahler, A.M., Williamson, J.R., Cech, T.R., and Prescott, D.M. 1991. Inhibition of telomerase by G-quartet DNA structures. Nature 350: 718-720.

Zaug, A.J., Podell, E.R., and Cech, T.R. 2005. Human POT1 disrupts telomeric G-quadruplexes allowing telomerase extension in vitro. Proc. Natl. Acad. Sci. 102: 10864-10869.

Zhu, J., Mayeda, A., and Krainer, A.R. 2001. Exon identity established through differential antagonism between exonic splicing silencerbound hnRNP A1 and enhancer-bound SR proteins. Mol. Cell 8: 1351-1361. 

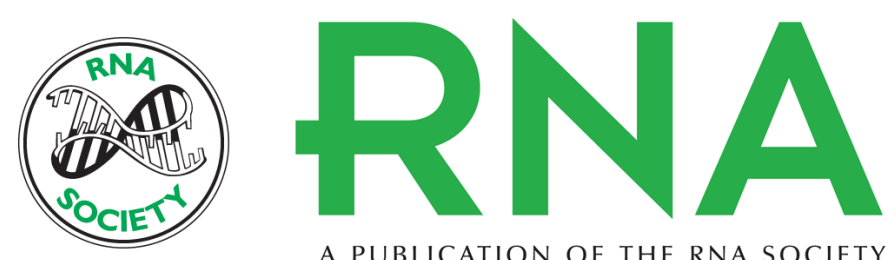

A PUBLICATION OF THE RNA SOCIETY

\section{hnRNP A1 associates with telomere ends and stimulates telomerase activity}

Qing-Shuo Zhang, Lisa Manche, Rui-Ming Xu, et al.

RNA 2006 12: 1116-1128

References This article cites 51 articles, 22 of which can be accessed free at:

http://rnajournal.cshlp.org/content/12/6/1116.full.html\#ref-list-1

License

Email Alerting Receive free email alerts when new articles cite this article - sign up in the box at the Service top right corner of the article or click here. 